\title{
The Effect of Oral Melissa officinalis on Serum Oxidative Stress and Second Degree Burn Wounds Healing
}

\author{
Masumeh Abbasdust Arbastan1, Kobra Rahzani ${ }^{2 *}$, Davood Hekmatpou' \\ Shaban Ali Alizadeh ${ }^{3}$, Mohammad Rafiei ${ }^{4}$, Ali Akbar Malekirad ${ }^{5}$ \\ ${ }^{1}$ Nursing Department, Arak University of Medical Sciences, Arak, Iran \\ ${ }^{2}$ Faculty of Nursing and Midwifery, Arak University of Medical Sciences, Arak, Iran \\ ${ }^{3}$ Faculty of Medicine, Arak University of Medical Sciences, Arak, Iran \\ ${ }^{4}$ Department of Social Medicine, Arak University of Medical Sciences, Arak, Iran \\ ${ }^{5}$ Department of Biology, Payame Noor University, Tehran, Iran \\ Email: ${ }^{*}$ K.rahzani@yahoo.com
}

Received 14 August 2014; revised 30 September 2014; accepted 15 October 2014

Copyright (C) 2014 by authors and Scientific Research Publishing Inc.

This work is licensed under the Creative Commons Attribution International License (CC BY). http://creativecommons.org/licenses/by/4.0/

(c) (i) Open Access

\section{Abstract}

For this aim, this study conducted in order to assess the effect of lemon balm as an antioxidant on second degree wound healing and oxidative stress serum of burning patients. To meet the aim, 60 patients with 15 to 50 burn percent with the age range of 18 to 50 were invited after considering to inclusion criteria by the researchers. First they have been put by non-probable method and then random method in two groups of experiment ( 30 people) and control ( 30 people). After that, experiment group in addition to ordinary treatment has been used Melissa officinalis (lemon balm) plant two times a day for two weeks $(1.5 \mathrm{~g}$ in $100 \mathrm{cc})$. Oxidative stress parameters included serum total antioxidant and the rate of malondialdehyde (MDA) that is one of total production of lipid peroxidation have been measured in patients' blood sample in first and last parts of the study. The wound position has been studied by using standard wound BATES-JENSEN assessment tool in first, seventh and fifteenth days of study. In order to analyze data, independent sample t-test, paired sample t-test and repeated measurement variance have been used. These results indicated that the state of wound healing in experimental group was better than that in control group. Results indicated that mean of serum total antioxidant had been increased in both groups. The index of lipid peroxidation at the end of period has been increased in experiment group than control group, whether this index is significantly decreased at the end of 15 days in experimental group. According to the results of this study, the effect of Melissa officinalis (lemon balm) plant was effective in increasing lipid peroxideative in better states of second degree burn wound healing.

\footnotetext{
${ }^{*}$ Corresponding author.
}

How to cite this paper: Abbasdust Arbastan, M., Rahzani, K., Hekmatpou, D., Alizadeh, S.A., Rafiei, M. and Malekirad, A.A. (2014) The Effect of Oral Melissa officinalis on Serum Oxidative Stress and Second Degree Burn Wounds Healing. Health, 6, 2517-2524. http://dx.doi.org/10.4236/health.2014.618290 


\section{Keywords}

\section{Burn Wounds Healing, Lemon Balm, Oxidative Stress}

\section{Introduction}

Burn is one of the most important difficulties in the world which has been followed by many morbidity and mortality in addition to changing life quality of patients. In burns, oxidative system changes have been revealed by increasing in activity of free radicals and lipid peroxidation and also salient reducing can be observed in total antioxidant and the capacity of cleaning anti-oxidative. Two main resources in reactive oxygen species (ROS) in burns are xanthine oxidase enzyme (XO) and increasing activity of neutrophil [1].

Many studies indicated that in burns following by producing toxins like (ROS), systematic inflammatory reaction has been started which leads to lipid peroxidation. Following by lipid peroxidation the hurt in cellular membrane has been occurred and finally cell has been died. Close relationship recorded between lipid peroxidation and burn complications. One of total productions in lipid per oxidation is malondialdehyde (MDA). Many studies have been shown that ischemia-reperfusion damage is along with increasing MDA level in tissues and different organism. In common situation, body is able to defend against free radicals damage with antioxidative mechanism like enzymatic system, vitamins, mineral elements and some antioxidative molecules. But, in situation like burns that balance has been lost between producing and removing free radicals from cells and tissues by yielding a lot of free radicals, oxidative stress has been created. So, clinical reply to this burn has been done based on balance between producing free radicals and removing them [2].

Antioxidants can decrease lipid peroxidation by reducing these items: oxygen concentration, cleaning free radicals, preventing from starting free radicals production, analyzing peroxides and breaking attraction chain of hydrogen free radicals [3]. Protecting of oxidative damage can be done by endogenous antioxidative activity or exogenous (like people diet) [4].

In some researches, vitamin $\mathrm{E}$, vitamin $\mathrm{C}$, sulfate zinc, allopurinol, melatonin and $\mathrm{N}$-acetyl cysteine (NAC) have been used as industry oxidant in burn patients that cause improving in curing in burn [1] [5]. There would be this belief that drug plants are potential sources of antioxidant and cleaning ROS molecules. In some studies some types of plants like Echium amoenum Fischin (Ranjbar et al., 2009) and Melissa officinalis [3] [6]-[9] have been used as full antioxidant resource. Lemon balm is a kind of plants that belong to Lamiaceae that has been grown in center and south of European, Asia and north part of Iran. Other names of it are Varangboo and Faranjmoshkin in Iran [3]. The extract of this plant has been used for preventing from neurologic patients related to oxidative stress [10] and improving cognitive function in patients who are suffering from amnesiac [11].

Also, infusion of this plant is applicable in these items: enforcing memory \& comprehension and stimulating stomach, anti-convulsion, dyspnea, improving in joint ache, curing headache, curing heartbeat, tranquilizing features, and anemia and curing dry skin [12]. Regarding destructive effects of free radicals and oxidative stress on patients who are suffering from burn and specially their role in revealing inflammatory reactions and secondary tissue damages and also willing to using natural antioxidant and limiting the number of researches on natural antioxidants, the researchers were going to conduct this research on the effect of lemon balm on oxidative stress level of patients serum and improve them. Although there are some researches on the effect of lemon balm antioxidants, regarding the relationship between free radicals in burn and repairing injury and also the lack of study in this matter in burn patients. If this plant is effective on anti-oxidative system in patients and improving injury, it can be possible to use it as supplementary treatment in patients and in addition to reducing bedridden period and treatment charges can improve their life quality.

\subsection{Bates-Jensen Wound Assessment Tool}

The Bates-Jensen wound assessment tool (Barbara Bates-Jensen, 2001), is a validated wound assessment tool that evaluates 13 wound characteristics (size, depth, edges, undermining, necrotic tissue type, necrotic tissue amount, exudate type, exudate amount, skin color surrounding wound, peripheral tissue, peripheral tissue indurations, granulation tissue, and epithelialization) with each item scored on a 1-5 scale. A total score is obtained by adding all individual scores and the results are plotted on the wound status continuum. Higher total scores in- 
dicate a more severe wound status.

\subsection{Statistical Analysis}

Statistics analysis stats direct 2.7.9 was used to analyze data. Kolmogorov-Smirnov test was applied (K-S test) to check whether the data were normally distributed. Finally using paired t-test and repeated measurement variance were compared. $p$ value less than 0.05 was considered as significant.

\section{Method and Materials}

This study is a clinical trial research was conducted on 60 patients (16 females and 44 males) in the age range of 50 - 18 years with 50 - 15 burn percentage (estimated based on Bravder Landau chart). These patients admitted to Vali-Asr University Hospital of Arak between December 2012 and June 2013. At first patients are likely to be selected by the investigator and then randomly were placed in two groups of experimental $(n=30)$ and control $(n=30)$. Before entering to this study, patients filled out the form of satisfying in participating to this research of Medical Science in Arak University. The study was approved in Ethical Committee of Medical Science in Arak University. All samples participated as volunteer and could go out from this research in every stage. The criteria for entering to this research were included: The participants didn't NPO and pregnant. They didn't affected by diseases such as thyroid disorders, diabetes, cancer and infection diseases, their reason for burn shouldn't be electrical reasons, they shouldn't be addicted or use alcohol and they were not under treatment by antioxidants or anti depression drugs. The criteria for extracting participates from this study were the lack of coordination for attending to study, possible allergy to lemon balm, patients discharge, transferring to other hospital or patients' death.

In beginning of the study, one questionnaire which made by researchers has given to participants to fill it out. Some questions about their injury, burn, demographic features and their social-economical situation. Then experimental group have been drunk lemon balm infusion which contains 1.5 gr dried sheet of it in 100 cc water and two times in one day ( 9 am $\& 9 \mathrm{pm}$ ) for two weeks, in addition to receiving daily routine care such as daily dressing in burn part. Related information on anti-oxidative serum level of two groups investigated in which Venus blood sample (5 cc) were taken for routine experiments in first and fifteenth days of the research. The blood sample of participants were centrifuged and they have been kept in $-70^{\circ} \mathrm{C}$ until their analyze. In the beginning of the research, $7^{\text {th }}$ and $15^{\text {th }}$ days the injury position investigated by standard instruments (Bates-Jensen) by researchers. Oxidative stress parameters included serum total antioxidant and lipid peroxidations are measured [13].

\section{Preparation of Protocol and Infusion}

Infusing based on standard protocol has been done by people who were expert. After cleaning dried leaves of lemon balm, they have been packaged on 1.5 gr boxes. Infusion has been prepared by mixing one box (1.5 gr) with 100 cc water in $98^{\circ} \mathrm{C}$ for 30 minutes [3].

\section{Results}

The age average of participants was 30.862 in experimental group and 30.241 in control group. In experimental group 21 people (70\%) and in control group 23 people (76.6\%) were males. Also, 9 people (30\%) in experimental group and 7 people (76.6\%) in control group were females. The means of burn percent in experimental group and control group were $23.83 \%$ and $24 \%$, respectively. Frequency distribution of burn depth in experimental and control subjects in Table 1 is shown.

The mean scores of investigating in jury in $1^{\text {st }}, 7^{\text {th }}$ and $15^{\text {th }}$ days were $33.63,24.7$ and 16.87 in experimental group and were 32.53, 28.03 and 25.07 in control group. As results indicated injury position in first day was similar in both experimental and control group, while it seems amplitude change in repairing injury in second and third periods ( $7^{\text {th }}$ and $15^{\text {th }}$ days) which were more than amplitude changes in control group (Table 2). $1^{\text {st }}$ day mean \pm SD values for MDA plasma levels in intervention and control groups were $15.55 \pm 16.35$ and $0.10 \pm 16.86$, respectively. $15^{\text {th }}$ day mean \pm SD values for MDA plasma levels in intervention and control groups were $10.18 \pm$ 3.55 and $0.53 \pm 11.44$, respectively. $1^{\text {st }}$ day mean \pm SD values for FRAP plasma levels in intervention and control groups were $0.252 \pm 0.063$ and $0.276 \pm 0.069$, respectively. $15^{\text {th }}$ day mean \pm SD values for FRAP plasma 
Table 1. Frequency distribution of burn depth in experimental and control subjects.

\begin{tabular}{ccccc}
\hline Index & Group & Type & Subject frequency & Relative frequency \\
\hline \multirow{2}{*}{ Control } & I, II & 1 & $3.3 \%$ \\
& & II & 20 & $66.7 \%$ \\
Burn depth & III & 8 & $26.7 \%$ \\
\cline { 2 - 5 } & & II, III, IV & 1 & $3.3 \%$ \\
\hline \multirow{2}{*}{ Experimental } & I, II & 1 & $3.3 \%$ \\
& & II & 10 & $33.3 \%$ \\
& & II, III & 17 & $56.7 \%$ \\
\hline
\end{tabular}

levels in intervention and control groups were $0.260 \pm 0.060$ and $0.284 \pm 0.061$, respectively (Table 2). The meaningful level of Kolmogorov-Smirnov indicated for studied indexes in both groups. These rates obtained bigger than 0.05 and as a result variables in every part of experiment are normal. So, conducting paired t-test and also repeated measurement variance was used. The result of repeated measurement variance presented that pattern changes of this index in experimental group are different from control group during three stages (first day, later 7 days and later 15 days) in meaningful level of first type (0.05). Of course, we should take into account that the rate of wound in both groups are improving but the rate of improved wound in experimental group is meaningful than control group as it is obvious in Figure 1. Also the meaningful test of groups' encounter effects and scores in improved wound in three turns indicated meaningful difference in improved wound score in both groups in every stage. Although, their basic scores didn't have significant difference, this interval registered in the rate of their improved wound in $2^{\text {nd }}$ and $3^{\text {rd }}$ periods (in $7^{\text {th }}$ and $15^{\text {th }}$ days) after beginning of the treatment.

MDA is one of the productions which derived from decomposing lipid peroxidation and was measured as lipid peroxidative index. Also the rate of final antioxidant capacity (FRAP) was considered as total antioxidant of serum. The mean of total antioxidant has been increased in both groups but it is not possible to claim about meaningful changes in this index. For lipid peroxidation has been observed that this index has been increased at the end of period than first day. While, this index had significant decrease in experimental group at the end of 15 days period.

The meaningful level of $\mathrm{T}$ test of paired sample obtained mean of total antioxidant in patients or control group ( $p=0.861)$ and experimental group $(p=0.505)$ that is bigger than first error $(0.05)$ and as a result the hypothesis about equal amount of final mean antioxidants is not rejected in first and end of study in every group (Table 3). So, regarding the results of this study, there isn't evidence on the effectiveness of lemon balm on the mean of patients' final antioxidants. The mean of lipid peroxidation in control group was $(p=0.034)$ and experimental group $(p=0.059)$. By comparing this meaningful level with first error $(0.05)$, it can be claim that the rate of patients' lipid peroxidation in control group has meaningful difference in first and end of research period (Table 4). It can be conclude that the rate of lipid peroxidation mean is more than mean at the end of period regarding negative part in the test and also mean differences in this group. But, it is observable that there isn't meaningful difference between mean in first and end of research regarding meaningful level for experimental group. So, using lemon balm has significant effect on lipid peroxidation mean of patients who suffering from burn. In order to investigate the correlation between wound healing and oxidative stress level, spearman correlation coefficient has been used. The greater amount of meaningful level in correlation test in 0.05 error indicated that there isn't meaningful correlation between any of oxidative stress level with wound healing based on two factors of lipid peroxidation and serum total antioxidant and it is true for both groups. So it can be concluded that oxidative stress level that lead to wound healing in patients who suffering from burn has not been studied.

In this regard, Bonferroni test has been used for investigating created differences in the rate of improved wound. The results of aforementioned test presented that improved wound's scores decreased in every period than previous period in experimental group. But in control group, improved wound had meaningful difference only 7 days after starting period. But this rate was not different in 15 days after starting period (Table 5, Table $6)$. 
Table 2. The concentrations' indexes and dispersion of research variables.

\begin{tabular}{cccc}
\hline Case group & Control group & Steps & Parameters \\
\hline $33.63 \pm 4.43$ & $32.53 \pm 6.45$ & First day & \\
$24.7 \pm 6.36$ & $28.03 \pm 6.59$ & Later 7 days & Improved injury score \\
$16.86 \pm 7.28$ & $25.06 \pm 6.20$ & Later 15 days & \\
$0.252 \pm 0.063$ & $0.276 \pm 0.069$ & First day & \\
$0.260 \pm 0.060$ & $0.284 \pm 0.061$ & Later 15 days & TAC $\left(\mathrm{mmol} \cdot \mathrm{mL}^{-1}\right)$ \\
$15.55 \pm 16.35$ & $18.10 \pm 16.86$ & First day & \\
$10.18 \pm 3.55$ & $29.53 \pm 11.44$ & Later 15 days & LPO $\left(\mathrm{nmol} \cdot \mathrm{mL}^{-1}\right)$ \\
\hline
\end{tabular}

Table 3. The concentration of total antioxidant in case and control group before and after the study.

\begin{tabular}{cccccc}
\hline Parameters & $\mathrm{N}$ & Difference mean & $\mathrm{t}$ & $\mathrm{df}$ & $p$ value \\
\hline Control group & 24 & 0.003125 & 0.1178 & 23 & 0.861 \\
Case group & 21 & 0.007286 & -0.679 & 20 & 0.505 \\
\hline
\end{tabular}

Table 4. The concentration of lipid peroxidation in case and control group before and after the study.

\begin{tabular}{cccccc}
\hline Parameters & $\mathrm{N}$ & Difference mean & $\mathrm{t}$ & $\mathrm{df}$ & $p$ value \\
\hline Control group & 25 & 9.484 & 2.248 & 24 & $0.034^{*}$ \\
Case group & 21 & -6.865 & -2.003 & 20 & 0.059 \\
\hline
\end{tabular}

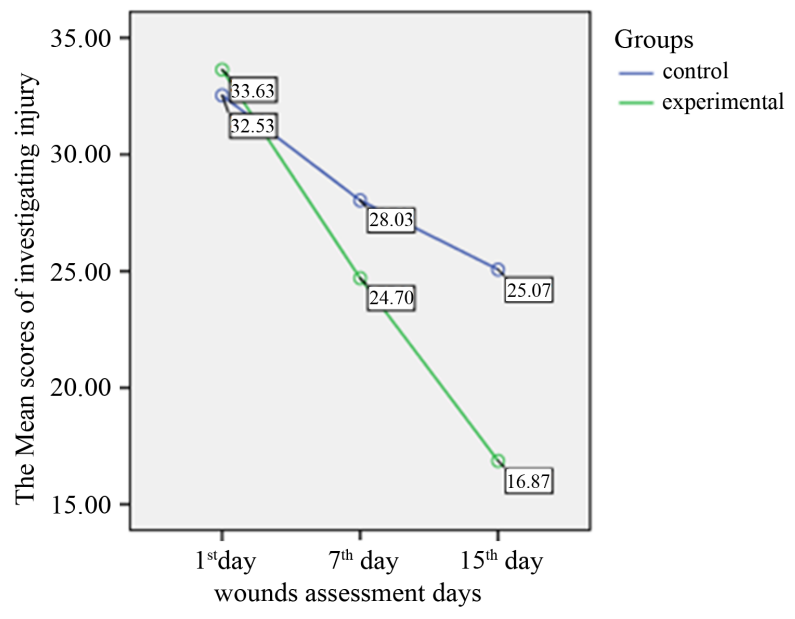

Figure 1. Mean of total score of wounds assessment in both of groups in assessment days is shown. Higher total scores indicate a more severe wound status.

\section{Discussion}

In present study, the effects of lemon balm infusion has been investigated on second grade burning wound healing and the state of serum oxidative stress in bedridden patients in burn unit. Results indicated significant development in the rate of wound healing in patients who used the infusion. On the other hand, from beginning to the end of research, the amount of MDA as lipid peroxidation index didn't increased in experimental group compared to control group. 
Table 5. The result of repeat measure analyses for improve in experimental and control group.

\begin{tabular}{cccccc}
\hline Source of change & Sum of squares of deviations from the mean & df & Mean square deviations from the mean & F & $p$ value \\
\hline Effect of steps measurement & 4421.744 & 2 & 2210.872 & 0.282 & $<0.001^{*}$ \\
Effects of group differences & 544.272 & 1 & 544.272 & 5.909 & $0.018^{*}$ \\
Process-group interaction & 649.144 & 2 & 324.572 & 0.588 & $<0.001^{*}$ \\
Effect of in-group error & 1533.111 & 116 & 13.216 & 92.102 \\
Effects of intergroup error & 5341.922 & 58 & & \\
\hline
\end{tabular}
${ }^{*} p<0.05$.

\begin{tabular}{lccccc}
\multicolumn{7}{l}{ Table 6. Changes in the three stages of healing scores (Bonferroni test). } \\
\hline Index & Step & Step & The difference between the two & Deviation error & $p$ value \\
\hline & 1 & 2 & -8.933 & 1.586 & $0.000^{*}$ \\
Case group & 2 & 3 & -7.833 & 1.586 & $0.000^{*}$ \\
& 1 & 3 & -16.766 & 1.586 & $0.000^{*}$ \\
& 1 & 2 & -4.50 & 1.658 & $0.024^{*}$ \\
Control group & 2 & 3 & -2.966 & 1.658 & 0.231 \\
& 1 & 3 & -7.466 & 1.658 & $0.000^{*}$ \\
\hline$p<0.05$. & & & & &
\end{tabular}

In burns, inflammatory cells produce ROS as a part of microbicidal vesitocid system. As previously mentioned, a lot of studies indicated that systematic inflammatory reactions begin which followed by producing toxins like ROS and finally lead to creating lipid peroxidation. Because of the main part of cell membranes is composed of polyunsaturated fatty acids (PUFA) which is the most vulnerable target of ROS attack and many tissues suffering from damaging in cell membranes peroxidation and finally cause to cellular death. In other side, there is close relationship between the amount of lipid peroxidation and burn complications.

Produced MDA which is one of total productions of lipid peroxidation is known as suitable index for oxidative damages. A lot of researches indicated that damage in perfusion is followed by increasing MDA level in organisms and different tissues. On the other hand, in first phase of burn, collecting neutrophils has been observed that known as another source for producing ROS in distant organs in damaged pathogenesis [2]. Other main sources of producing free radicals (ROS) in burning trauma is xanthine oxidase enzyme which has important role in ischemia reperfusion damage by producing destructive free radicals in cleaning capacity in endogenous enzymes [3]. According to producing free radicals in burn occur a remarkable decrease in total antioxidant status and antioxidantive cleaning capacity [1]. In this situation, there is a lot of free radicals production and unsuitable application in antioxidants system. So, this balance between producing and removing free radicals failed in cells and tissues and there would be situation like oxidative stress. So, clinical responses have been done based on keeping this balance [2].

Lemon balm is a kind of plant with natural antioxidants and is effective in many related disease to oxidants [6]. In vitro \& ex vivo studies, antioxidant activity in lemon balm has been shown but there are limited disease to oxidative stress studies particularly related to human. In vivo studies, lemon balm extract just was able to decrease LPO rate in rodents and hyperlipidemic liver in rats. Lemon balm extract as a full resource of very useful antioxidants and many researches indicated great amount of phenolic in polar extract and antioxidants activity and cleaning capacity in free radicals. These components have antioxidants and cleaning free radicals and also, decreased LPO rate [3].

Some studies used of various antioxidants to antagonize ROS in burned patients; such as: vitamin E, vitamin C, zinc sulphate, allopurinol, N-acetylcysteine [1] [5] and melatonin [5].

In those studies MDA were significantly increased at zero time in burn patients $(p>0.05)$ when compared with healthy subjects (control group). In group that didn’t use antioxidant, serum MDA levels were non-signifi- 
cantly decreased on days 3, 7, and 14 compared with zero time, while on discharge day serum MDA levels were significantly decreased by $61.37 \%$ compared with zero time. This result was still significantly higher than control group.

The main phenolic compounds that were identified in tea infusion from lemon balm, respectively were rosmarinic acid, luteolin 7-o-glucoside, quercetin 3-rutinoside, gallic acid, quercetin 3-o galactoside and ferulic acid. Recent studies indicated that the oral administration of lemon balm is beneficial in protection against oxidative stress and DNA damage in subjects exposed to long-term low-dose ionizing radiation and fatty liver diseases that a significant decrease ( $p=0.0001)$ in LPO level and liver enzyme were observed [3] [14]. Also may be useful for the protection of aluminium worker from toxic effects of that is mediated through oxidative stress [8]. In this study antioxidant parameters significantly increased but LPO was not different before and after use of lemon balm infusion.

Some studies used medicinal plants in second-degree burn wounds healing such as onosma stenosiphon boiss that assessed on gerbil (field mouse) (rat) [15], or alcoholic extract of Camellia sinensis that assessed on burn wounds in gerbil [16]. In these studies a significant improvement in wound healing were shown. In recent study antioxidant effects of Camellia sinensis has been used. Also, using lemon balm infusion didn't significantly increase serum MDA as an index of LPO. Therefore, MDA that is a product of lipid peroxidation is decreased and significantly improved wound healing in burn patients.

\section{Conclusion}

The oral administration of lemon balm infusion may be helpful for improving antioxidant defense system by decreasing LPO help to second-degree burn wounds healing. These findings encourage pursuing further studies such as determining effects of lemon balm on other degree burn wounds healing and healing time. As limitation of this study, the researchers were not able to control other antioxidants that they intake exactly because of ethical reasons.

\section{Acknowledgements}

The authors would like to thank all subjects and burn ward staff of Valiasr Hospital in Arak for their kind cooperation.

\section{Authors Note}

This study was the outcome of an MA thesis of the first author in Arak University of Medical Sciences.

\section{References}

[1] Al-Javad, F.H., Sahib, A.S. and Al-Kaisy, A.A. (2008) Role of Antioxidants in the Treatment of Burn Lesions. Annals of Burns and Fire Disasters, 21, 186-191.

[2] Parihar, A., Parihar, M.S., Milner, S. and Bhat, S. (2008) Oxidative Stress and Anti-Oxidative Mobilization in Burn Injury. Burns, 34, 6-17. http://dx.doi.org/10.1016/j.burns.2007.04.009

[3] Zeraatpishe, A., Oryan, Sh., Bagheri, M.H., Pilevarian, A.A., Malekirad, A.A., Baeeri, M., et al. (2011) Effects of Melissa officinalis L. on Oxidative Status and DNA Damage in Subjects Exposed to Long-Term Low-Dose Ionizing Radiation. Toxicology and Industrial Health, 27, 205-212. http://dx.doi.org/10.1177/0748233710383889

[4] Ranjbar, A., Khorami, S., Safarabadi, M., Shahmoradi, A., Malekirad, A.A., Vakilian, K., et al. (2006) Antioxidant Activity of Iranian Echium amoenum Fisch \& C. A. Mey Flower Decoction in Humans: A Cross-Sectional before/after Clinical Trial. Evidence-Based Complementary and Alternative Medicine, 3, 469-473. http://dx.doi.org/10.1093/ecam/nel031

[5] Sahib, A.S., Al-Jawad, F.H. and Al-Kaisy, A.A. (2009) Burns, Endothelial Dysfunction, and Oxidative Stress: The Role of Antioxidants. Annals of Burns and Fire Disasters, 22, 6-11.

[6] Hasani-Ranjbar, Sh., Larijani, B. and Abdollahi, M. (2009) A Systematic Review of the Potential Herbal Sources of Future Drugs Effective in Oxidant-Related Disease. Inflammation \& Allergy-Drug Targets, 8, 2-10. http://dx.doi.org/10.2174/187152809787582561

[7] Dragland, S., Senoo, H., Wake, K., Holte, K. and Blomhoff, R. (2003) Several Culinary and Medicinal Herbs Are Important Sources of Diateryantioxidants. American Society for Nutritional Sciences, 133, 1286-1290. 
[8] Fazli, D., Malekirad, A.A., Pilevarian, A.A., Salehi, H., Zerratpishe, A., Rahzani, K., et al. (2012) Effect of Melissa officinalis L. on Oxidative Status and Biochemical Parameters in Occupationally Exposed Workers to Aluminium: A before after Clinical Trial. International Journal of Pharmacology, 8, 455-458. http://dx.doi.org/10.3923/ijp.2012.455.458

[9] Sajjadi, A., Naderi, G.H. and Ziayi, R. (2004) Antioxidant Effects of Selected Medicinal Plants of the Mint Family. Journal of Kermanshah University of Medical Sciences, 21, 1-12.

[10] Pereira, R.P., Fachinetteo, R., Prestes, A.D.S., Puntel, R.L., Silva, G.N.S.D., Heinzmann, B.M., et al. (2009) Antioxidant Effect of Different Extracts from Melissa officinalis, Matricaria recutita and Cymbopogon citratus. Neurochemical Research, 34, 973-983. http://dx.doi.org/10.1007/s11064-008-9861-z

[11] Akhondzadeh, S., Noroozian, M., Mohammadi, M., Ohadinia, S., Jamshidi, A.H. and Khani, M. (2003) Melissa officinalis Extract in the Treatment of Patients with Mild to Moderate Alzheimer's Disease: A Double Blind, Randomised, Placebo Controlled Trial. Journal of Neurology, Neurosurgery Psychiatry, 74, 863-866. http://dx.doi.org/10.1136/jnnp.74.7.863

[12] Farhani, T. and Najafi, F. (2012) Medicinal Plants (Balm). Rashedin Publication, Tehran, 34-37.

[13] Fani, A., Malekirad, A.A., Allahnazem, H., Rahzani, K., Ranjbar, A., Vosough-Ghanbari, S. and Abdollahi, M. (2008) On the Benefit of Cinnamomum zeylanicum for Radiology Unit Staff. The Journal of Medical Sciences, 8, 384-389. http://dx.doi.org/10.3923/jms.2008.384.389

[14] Malekirad, A.A., Mojtabaee, M., Faghih, M., Vaezi, G. and Abdollahi, M. (2012) Effects of the Mixture of Melissa officinalis L., Cinnamomum zeylanicum and Urtica dioica on Hepatic Enzymes Activity in Patients with Nonalcoholic Fatty Liver Disease. International Journal of Pharmacology, 8, 204-208. http://dx.doi.org/10.3923/ijp.2012.204.208

[15] Khalili, M.A., Esmaeeli, M., Moghaddam, H., Rezaee, S.H. and Vahidi, A.R. (2010) Therapeutic Effect of Onosma Stenosiphon Boiss on Gerbils with Second-Degree Wounds in Back and Testis. Journal of Herbal Drug, 1, 29-34.

[16] Asadi, Y., Zamiri, A., Ezzati, S., Parsayi, P., Rafieiyan, M. and Shirzad, H.A. (2010) Effect of Camellia sinensis Alcoholic Extract on Burn and Surgical Wounds Healing in Gerbils. Journal of Birjand University of Medical Sciences, 1, $1-9$.

\section{Abbreviations List}

PRN: pro re nata, as needed;

LPO: lipid peroxidation;

ROS: reactive oxygen species;

XO: xanthine oxidase enzyme;

MDA: malondialdehyde;

NAC: N-acetyl cysteine;

TAC: total antioxidant capacity;

PUFA: poly unsaturated fatty acids;

NPO: nulla per os. 
Scientific Research Publishing (SCIRP) is one of the largest Open Access journal publishers. It is currently publishing more than 200 open access, online, peer-reviewed journals covering a wide range of academic disciplines. SCIRP serves the worldwide academic communities and contributes to the progress and application of science with its publication.

Other selected journals from SCIRP are listed as below. Submit your manuscript to us via either submit@scirp.org or Online Submission Portal.
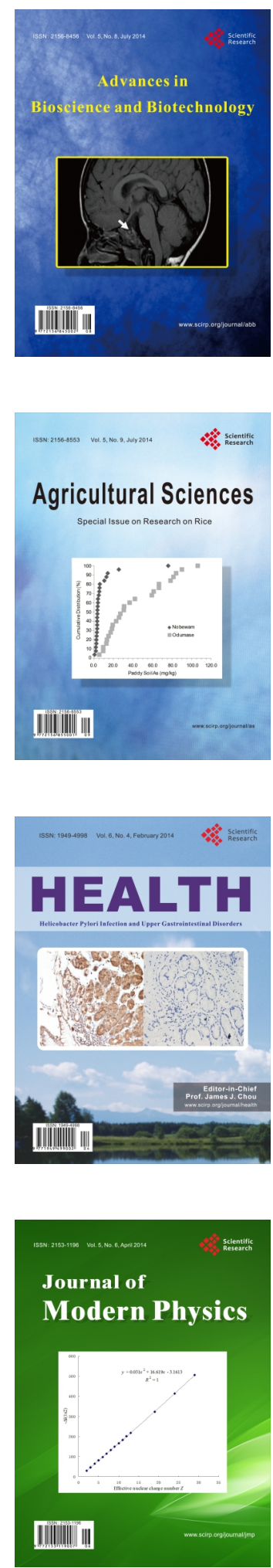
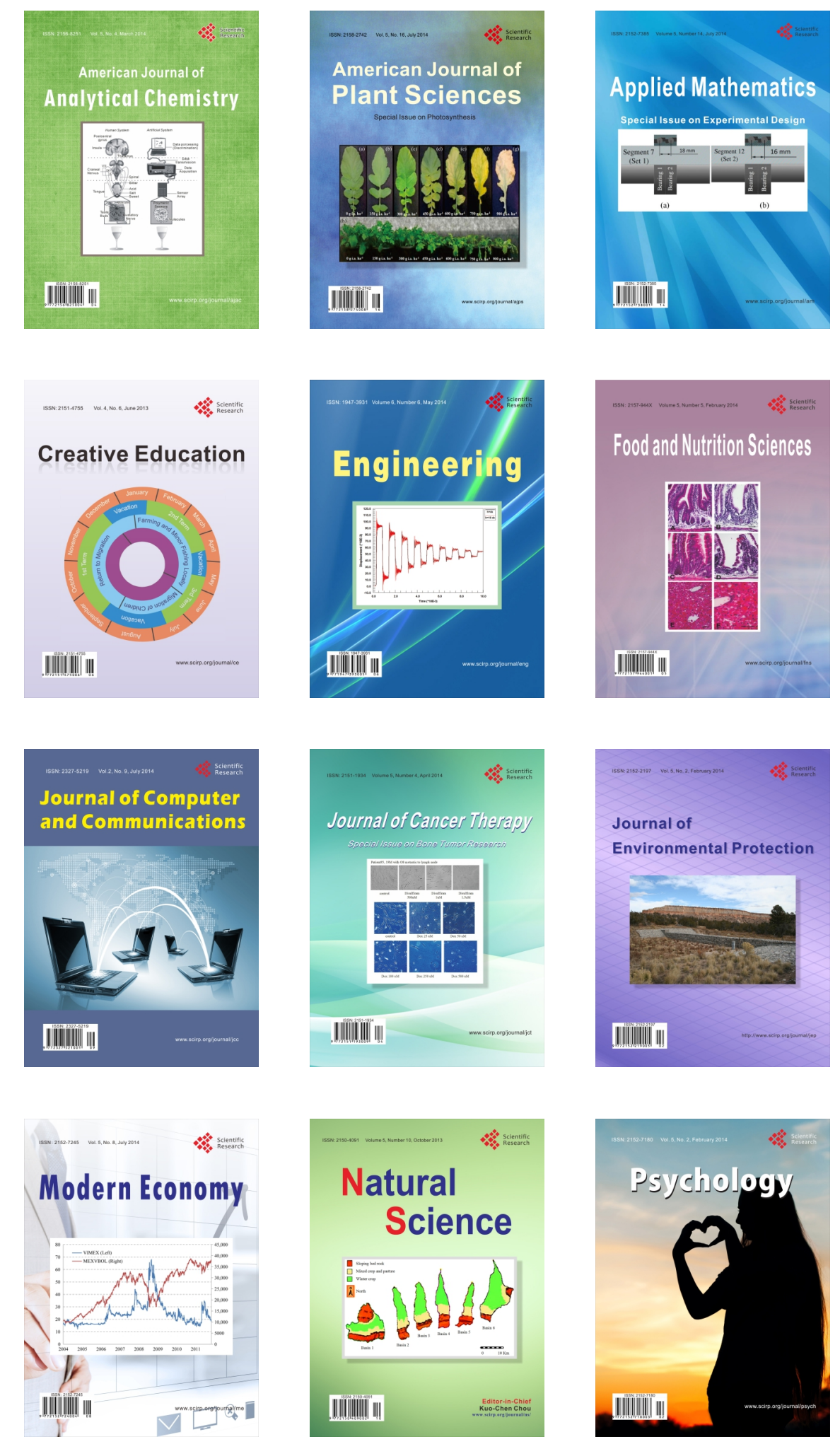